\title{
莯 revistainvi
}

Volumen 36, nro.103, noviembre 2021 ISSN 0718-1299

El diseño político del proceso de financiarizacionte la. vivienda y la infraestructura en Chile

Recibido: 2021-05-31.

Aceptado: 2021-10-13.

Cómo citar este artículo:

Kornbluth Camblor, D. L. (2021). El diseño político del proceso de financiarización de la vivienda y la infraestructura en Chile. Revista INVI, 36(103), 54-84. https://doi.org/10.4067/S0718-83582021000300054

El artículo es producto de la investigación realizada entre 2015 y 2019 para optar al grado de Doctor en Ciencias Sociales, defendida en junio 2020, Facultad de Ciencias Sociales, Universidad de Chile. La investigación fue patrocinada por el Centro de Estudios de Conflicto y Cohesión Social (Proyecto FONDAP 15130009) y por Conicyt en el marco del programa de Formación de Capital Humano.

\section{David León Kornbluth Camblor}

Investigador postdoctoral en Programa Avanzado en Desigualdades y Desarrollo Sostenible - trAndeS, Santiago, Chile, dakornbluth@gmail. com

https://orcid.org/0000-0002-9930-2425 


\section{El diseño político \\ del proceso de \\ financiarización \\ de la vivienda y la \\ infraestructura en Chile}

\section{Resumen}

El artículo presenta resultados de una investigación que tuvo como objetivo analizar el rol del empresariado de la construcción en las transformaciones del capitalismo en Chile desde 1951 a 2018. Para ello se realizó un análisis de contenido documental y más de veinte entrevistas a actores clave del proceso, desde empresarios hasta ex ministros de Estado. Adicionalmente, se llevó a cabo un análisis de redes. Todo ello demostró, entre otras cosas, que el empresariado de la construcción chileno actúa simultáneamente como gremio, grupo de negocios y estructura de responsabilidad social empresarial, de manera altamente diversificada en varios sectores de la economía, lo cual le ha permitido ejercer liderazgo en el diseño político de los mercados en el marco del proceso de financiarización chileno. Los resultados que se presentan en el presente documento muestran la incidencia del empresariado de la construcción en la elaboración de los marcos institucionales que regularán las actividades financieras en el marco de la vivienda y la infraestructura desde 1951 en adelante.

Palabras clave: poder político; Cámara Chilena de la Construcción; empresariado; clases dominantes; elites. 


\section{Abstract}

The article presents the results of an investigation that aimed to analyze the role of construction entrepreneurs in the transformations of capitalism in Chile from 1951 to 2018. For this, an analysis of documentary content and more than twenty interviews with key actors in the process from businessmen to former ministers of state. Additionally, a network analysis was carried out. All this demonstrated, among other things, that the Chilean construction business acts simultaneously as a union, business group, and structure of Corporate Social Responsibility, in a highly diversified way in various sectors of the economy, which has allowed it to exercise leadership in the political design of the markets within the framework of the Chilean financialization process. The results presented in this document show the incidence of the construction business community in the elaboration of the institutional frameworks that will regulate financial activities in the framework of housing and infrastructure from 1951 onwards.

\section{The political design of housing and infrastructure financialization process in Chile}

Keywords: Political power; Chilean Construction Chamber; entrepreneurs; ruling classes; elites. 


\section{粼 revistainvi}

\section{Introducción}

El artículo presenta resultados de una investigación que tuvo como objetivo analizar el rol del empresariado de la construcción en las transformaciones del capitalismo en Chile desde 1951 al 2018. Para ello se realizó un análisis de contenido documental y más de veinte entrevistas a actores clave del proceso -desde empresarios hasta ex ministros de Estado-. Adicionalmente, se llevó a cabo un análisis de redes. Todo ello demostró, entre otras cosas, que el gremio de la construcción chileno actúa tridimensional y simultáneamente como asociación gremial, corporación de responsabilidad social empresarial y como grupo de negocio (empresarial) altamente diversificado en varios sectores e, incluso, internacionalizado, todo en base a una estructura de sociedades por acciones (Kornbluth, 2021). Dicha tridimensionalidad se aprecia en la Figura 1.

\section{Figura 1.}

Tridimensionalidad corporativa CChC.

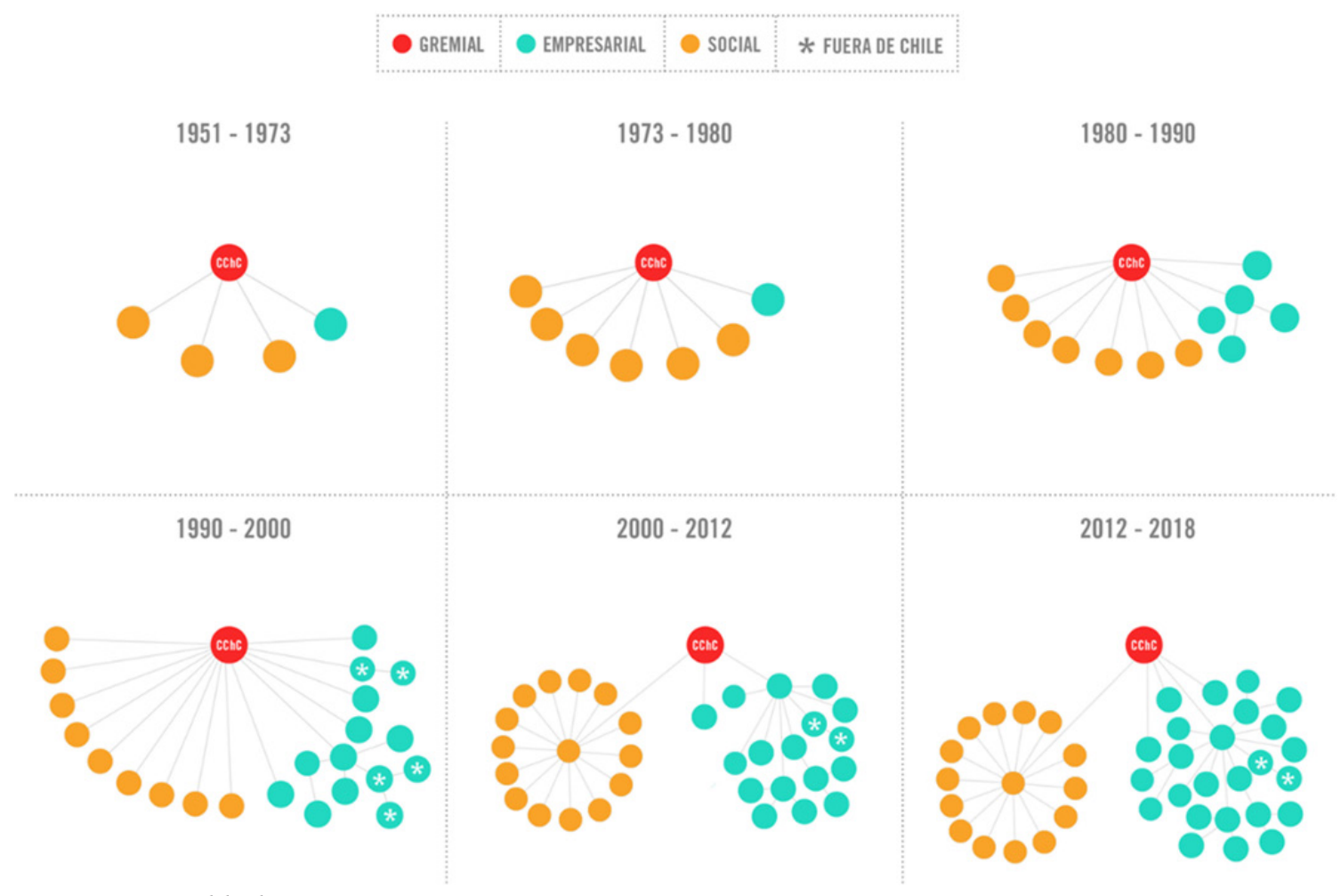

Fuente: Kornbluth, 2020a. 


\section{*.*vis revistainvi}

El gremio de la construcción comprende a la fecha más de dos mil ochocientos socios que van desde grandes empresas constructoras, inmobiliarias, concesionarias y proveedoras de materiales hasta pequeñas oficinas de arquitectos o profesionales. Los cargos son escogidos por votación mediante un sistema de democracia oligárquica (Arriagada, 1970; Kornbluth, 2020a). La mesa directiva ejercerá el control político de la asociación gremial (todas las corporaciones de distinta naturaleza que controla) y la interlocución con el Estado y otras instituciones durante su período de mandato (dos años generalmente).

Sin embargo, el propósito del artículo es puntualizar elementos del proceso político de toma de decisiones que posibilitaron la creciente financiarización en términos generales y específicamente con la vivienda y la infraestructura urbana en Chile. En dicho proceso, el gremio de la construcción desempeñó un papel principal en el diseño de políticas que fueron convertidas en normativa legal. Con el fin de demostrar esta relación se utilizan memorias institucionales de la Cámara Chilena de la Construcción y entrevistas realizadas en el marco de la investigación, además de algunas de las leyes que se promulgan a lo largo del período.

En específico, el presente artículo informa sobre el ejercicio político del empresariado de la construcción en el marco del proceso de financiarización chileno. Para ello, el texto se desarrolla en el siguiente orden. En primer lugar, se plantea la problemática que rodea el tratamiento del gremio de la construcción en Chile y sus distintas dimensiones institucionales; en segundo lugar, se despliega brevemente el marco metodológico y el enfoque teórico que siguió la investigación; en tercer lugar, se puntualizan resultados de la investigación en el marco del diseño político institucionalizado en Chile en el proceso de financiarización de la vivienda y el espacio urbano desde la década del cincuenta. Se tratan aquí algunas innovaciones corporativas por parte del empresariado de la construcción, pero, sobre todo, las innovaciones normativas en el sector público impulsadas por el sector privado de la construcción. A partir de los resultados de la investigación, se establecieron cuatro períodos de tiempo que logran explicar algunos patrones de la participación del gremio de la construcción en el proceso de financiarización chileno. Por último, se presentan conclusiones relacionadas con el poder político que acumulan los gremios -en este caso, el de la construcción- y la capacidad de influir sustantivamente en los marcos legales e institucionales durante el proceso de financiarización de la vivienda y el espacio urbano en Chile. 


\section{䌊 revistainvi}

\section{Problemática y estado del arte}

Las últimas décadas han dado cuenta del desarrollo conceptual de la financiarización como elemento central para comprender los cambios de la producción y la circulación en el régimen de acumulación capitalista a nivel mundial (Arrighi, 1994; Chesnais, 2001, 2017; Lapavitsas, 2016). La noción de financiarización ha sido prolífica, con focos en distintos elementos del fenómeno, que van desde el abandono del patrón oro (1971) hasta la disminución sostenida de la tasa de ganancia. Sin embargo, desde distintos puntos de vista se da un consenso en cuanto a la relevancia adquirida por el sector inmobiliario en el proceso de consolidación de las finanzas a nivel mundial. No en vano, la principal crisis financiera posterior al crack de 1929 está directamente anclada en la deuda hipotecaria (López-Morales y Gasic, 2021; McLean, 2013; Reinhart y Rogoff, 2011; Roubini y Mihm, 2010).

En principio, el debate sobre la financiarización fue mayormente tratado por economistas marxistas (Baran y Sweezy, 1969; Foster, 2007, 2008, 2010; Magdoff y Sweezy, 1987; Sweezy, 1973); sin embargo, con el pasar de los años y con mayor evidencia disponible, el interés por este proceso se amplió no sólo a otras corrientes, sino también a otras disciplinas como la geografía, sociología, antropología, filosofía, etc. (Alonso y Fernández Rodríguez, 2018; Appadurai, 2017; Caffentzis, 2018; Lazzarato, 2015).

Para abordar los entrelazamientos contemporáneos del capital financiero con la vivienda y la infraestructura, Hudson (2018) pone el énfasis en el sector FIRE (Finance, Insurance and Real Estate), destacando también dentro de la producción inmobiliaria la privatización de las infraestructuras cuyo fin es extraer renta monopolística. En la misma línea, Torrance (2008) apunta a la financiarización de las infraestructuras configurando un nuevo escenario de interconexión "glocal" de fondos de inversión. Aalbers (2015) desarrolla la noción de REFCOM (Real Estate Financial Complex), dando cuenta de las relaciones entre agentes privados inmobiliarios y financieros y el Estado. Lo relevante de ambos enfoques es la interconexión estructural que establecen entre el sector inmobiliario y el sector financiero en un entramado con relaciones de retroalimentación y funcionamiento complementario facilitado por el Estado (Fernández y Aalbers, 2016). Méndez (2018) apuntó con agudeza, desde una perspectiva geográfica, a señalar dicho entramado como una telaraña financiera. No obstante, para el presente artículo interesa principalmente la financiarización comprendida como la tendencia al predominio de la lógica financiera en la gobernanza corporativa del gremio de la construcción que impacta en la estructuración de las políticas públicas en vivienda e infraestructura.

Desde estos estudios se extraen elementos relevantes. Entre ellos, una heterogeneidad de actores financieros que van mucho más allá de los bancos (fondos de pensiones, fondos mutuos, compañías de seguros, fondos de inversión, etc.), multiplicidad de instrumentos financieros (swaps, CDO, bonos soberanos, etc.), un rol central de la deuda, y a raíz de esta, mayor participación de las clases trabajadoras (Aalbers, 2008; Hudson, 2018; Lapavitsas, 2016; Lazzarato, 2015; Lucarelli, 2009), y la necesidad de abordar también el proceso de financiarización desde miradas centradas en los procesos políticos (Appadurai, 2017; Kornbluth, 2020b). 


\section{*.*vis revistainvi}

Justamente, es esta última perspectiva la que guía el artículo, es decir, una noción quizás más clásica, anclada en los planteamientos de Rudolf Hilferding (quien acuñó la noción de capital financiero en 1910), señalando que el capital financiero toma posesión del aparato estatal para convertirlo en instrumento de sus intereses (Hilferding, 1963, p. 417).

\section{EMPRESARIADO DE LA CONSTRUCCIÓN: ANTECEDENTES}

Los últimos estudios que tratan el gremio de la construcción chileno como un objeto específico datan de la década del setenta (Arriagada, 1970; Cheetham, 1971). A pesar de que el sector de la construcción moviliza directamente un 8\% del empleo a nivel nacional (Instituto Nacional de Estadísticas, 2019), correspondiente a un 9\% del PIB, y que constituye una parte elemental de la élite económica, este no ha sido una problemática central para la Economía o la Sociología. En efecto, lo interesante del empresariado de la construcción es que aglutina simultáneamente los tres factores productivos clásicos, capital, trabajo y tierra (Lefebvre, 2013; Marx, 1973, 2015; Polanyi, 2017), situación que se profundiza en el proceso de financiarización.

El hecho de que convivan en una misma institución una asociación gremial, un área de responsabilidad social empresarial y una sociedad de inversiones o que el gremio de la Construcción sea el segundo prestador de servicios sociales más grande del país después del mismo Estado no ha despertado la curiosidad del Derecho, y su nacimiento y acompañamiento desde la década del cincuenta al Estado de Chile en materia de políticas públicas o su estructura de democracia oligárquica tampoco lo ha hecho en la historia o la ciencia política (Kornbluth, 2020a). La presente investigación viene a contribuir en la comprensión de ese vacío interdisciplinar que explique la dinámica y los impactos de la institucionalización de la representación política de los intereses empresariales presente en la historia contemporánea del Estado de Chile y sus transformaciones productivas en el marco de la financiarización de la vivienda y el espacio urbano.

Quizás el mayor interés sobre el gremio de la construcción chileno se despertó en los estudios urbanos en el marco de las políticas de vivienda, planes reguladores, gentrificación, periferización, y neoliberalización (Janoschka e Hidalgo, 2014; López Morales, 2015; Lukas, 2017; Sugranyes y Rodríguez, 2005). Estos estudios muestran la influencia del empresariado de la construcción chileno en el marco de la producción del espacio urbano y los mecanismos depredatorios de los intereses inmobiliarios en la ciudad con su correlativo impacto en el espacio y la producción de la ciudad. Otros artículos en una línea similar abordan genealógicamente las políticas neoliberales o el tipo realmente existente de neoliberalismo en Chile y sus impactos, como elementos tangenciales, pero sin siquiera referirse al poder político y económico empresarial en el diseño de dichos marcos (Garretón, 2017; Navarrete-Hernández y Toro, 2019).

Por último, se debe señalar que en el gremio de la construcción chileno conviven la estructura gremial (comités gremiales, comisiones asesoras del consejo nacional, el directorio y la mesa directiva), una estructura de responsabilidad social empresarial (con catorce entidades en áreas de cultura, deporte, primera infancia, educación, capacitación laboral, seguro y centros médicos, bienestar laboral, etc.). Y una estructura de sociedad por acciones desde la que se desprende el control de más de veinte sociedades por acciones en 


\section{粼 revistainvi}

áreas de (seguros, pensiones, prestación y seguro de salud, inmobiliaria, banco, etc.) y que han delimitado su trayectoria financiera en el marco de la gobernanza corporativa (Kornbluth, 2021).

\section{Materiales, métodos y enfoque}

El presente apartado aborda la metodología del estudio primario, especificando el paradigma en el que se inscribe, el enfoque de análisis adoptado y las técnicas de recolección y producción de datos utilizadas. Finalmente, la sección explicita la hipótesis de trabajo para el presente artículo.

La investigación se realizó entre el año 2015 al 2019 y se enmarcó en el paradigma cualitativo. Se constituyó como un análisis de caso desde un enfoque neo-institucional y socio-histórico con el fin de permitir una aproximación intensiva al objeto y el fenómeno estudiado (Bhattacherjee, 2012; Flick, 2014). En términos concretos, la investigación se orientó a comprender el rol del empresariado de la construcción en Chile a través del tiempo desde la década de 1950 hasta 2018.

Para ello, se construyó un enfoque anclado en las relaciones sociales de producción que fue construido sobre la base del análisis de clase (Wright, 2018; Zeitlin, 1980) del neoliberalismo realmente existente (Brenner et al., 2010; Brenner y Theodore, 2002; Theodore et al., 2009) y de las variedades de capitalismo (Hall y Soskice, 2001; Schneider, 2009).

Las técnicas utilizadas para producir los datos fueron, en primer lugar, un análisis de contenido documental que abarcó más de siete mil páginas de memorias anuales y publicaciones institucionales de la Cámara Chilena de la Construcción [CCHC] y las instituciones por él controladas desde 1951 hasta el 2018, las cuales serán citadas bajo el autor "CChC" con su año respectivo (1951-2018). En segundo lugar, se llevaron a cabo más de veinte entrevistas realizadas a distintos actores individuales que han sido parte u observadores privilegiados del fenómeno de la financiarización en Chile. Entre ellos, empresarios del sector de la construcción, dirigentes y ex dirigentes del gremio de la construcción, ex ministros de Estado y altos cargos públicos en instituciones del Estado relacionadas con el sector de la construcción (Ministerio de Vivienda y Urbanismo, Ministerio de Obras Públicas, Ministerio del Trabajo), ex gerentes de empresas privadas relacionadas con el sector o controladas por el gremio de la construcción, y algunos académicos del área de la economía y los estudios urbanos $^{1}$. A partir de esto se realizó un análisis cualitativo de contenido (Schreier, 2014). En tercer lugar, se realizó un análisis de redes tanto a nivel institucional como personal para mostrar la existencia de: i) relaciones entre el gremio de la construcción y sus industrias conexas; ii) relaciones entre el gremio de la construcción y las instituciones estatales; y iii) relaciones entre las propuestas privadas de política pública y la promulgación final de normativas en el campo económico, laboral y urbano en Chile entre 1951 y 2018 (Kornbluth, 2020a).

$1 \quad$ Las entrevistas citadas en el presente artículo son caracterizadas por perfil de los entrevistados y mantienen la numeración correspondiente a la codificación de la investigación. 


\section{*.*vis revistainvi}

\section{HIPÓTESIS}

Se sostiene como hipótesis del artículo que el empresariado de la construcción constituyó políticamente elementos que configuraron y fueron profundizando un proceso de financiarización de la vivienda y la infraestructura en Chile gracias a la articulación progresiva de un entramado institucional de capital endógeno al sector de la construcción que funciona paralela y complementariamente al mercado de capitales en general para promover la industria de la construcción y sus industrias conexas. Este entramado habría sido posible gracias a y retroalimentario de aquel poder político que este actor ostenta en Chile en el desarrollo del capitalismo mundializado.

\section{Resultados}

En un artículo anterior se ha discutido las transformaciones en la estructura de gobernanza corporativa del empresariado de la construcción chileno y se ha dado cuenta de su tendencia a la profundización en la participación de los circuitos de capital financiero en el marco del capitalismo en Chile durante siete décadas. El proceso descrito se inició en 1954 con la creación de una aseguradora que al 2018 decanta en una sociedad de inversiones controladora de veinte entidades, entre las que se cuenta una administradora de fondos de pensiones, una hipotecaria, varias aseguradoras, un fondo de inversión, un banco, etc., convirtiendo al gremio de la construcción en un grupo de negocios altamente diversificado capaz de movilizar un mercado de capital endógeno para el funcionamiento del sector (Kornbluth, 2021).

El propósito del presente artículo, más que centrarse en las magnitudes, flujos y dinámicas del capital financiero propiamente tal, corre por el carril paralelo de puntualizar el rol político del empresariado de la construcción chileno en el proceso de financiarización de la vivienda y del espacio urbano en Chile.

Un aspecto trascendente es que la normativa de lobby en Chile se promulgó el año 2014, por lo que la mayoría de los hitos que se puntualizan en el presente artículo no son entendidas institucional o legalmente como lobby. Específicamente, la discusión de esta ley se extendió desde 2007. El gremio de la construcción primero se opuso, y luego retrasó, sosteniendo que el gremio debía quedar fuera de entidades reguladas por esta ley, dado que su naturaleza no la convertía en un actor relevante para esta materia (CChC, 2008, 2009, 2010). Actualmente, los datos muestran al gremio de la construcción como el principal actor "lobbysta" en Chile (Figura 2), poniendo institucionalmente de manifiesto su rol político en el marco de la producción de leyes, normativas y políticas públicas. Antes de la entrada en vigencia de esta ley, las relaciones entre el gremio de la construcción y el empresariado se ubicaban en un campo difícil de explorar por su funcionamiento -en muchas oportunidades- extrainstitucional (Cortes Terzi, 2000). 
Figura 2.

Principales usuarios ley de lobby en Chile (2019-2021).
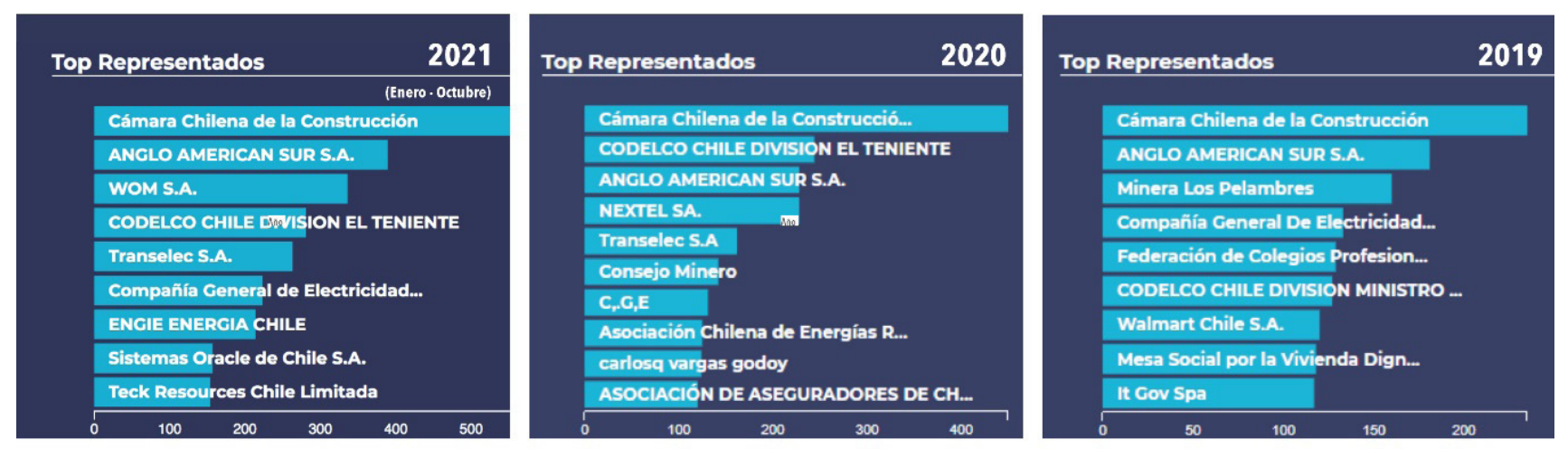

Fuente: elaboración propia en base a datos del Consejo para la Transparencia (CPLT).

De allí, los resultados ponen énfasis en mostrar las relaciones políticas que existen entre el gremio de la construcción y el Estado en perspectiva histórica en el marco del proceso de financiarización de la vivienda y el espacio urbano en Chile y cuyo impacto se evidencia en la promulgación de leyes y normativas que permiten (cuando no fortalecen), transformaciones en los modos de uso del capital financiero por parte del empresariado de la construcción desde principios de la década del cincuenta hasta nuestros días.

Para ello, se ha dividido en cuatro subcapítulos que corresponden a la periodización establecida en la investigación. El primer período va desde la fundación del gremio en 1951 hasta el golpe de Estado en 1973. Un segundo momento se extiende durante toda la dictadura militar (1973-1990). Un tercer período va desde 1990 hasta el 2012, momento de salida a bolsa de la sociedad por acciones controlada por el gremio. Finalmente, un último período va desde 2012 hasta 2018. Los resultados extraídos de cada uno de ellos se presentan a continuación.

\section{Constitución del GREMIO Y FLORECIMIENTO dE LA FinANCIARIZACIÓN DE LA VIVIENDA (1951-1973)}

Durante este período, el gremio de la construcción crea una sociedad securitizadora con el fin de extender las pólizas que debían tener las empresas de la construcción para ejecutar obras encargadas por el Estado. La Compañía de Seguros la Construcción nace en 1954 y será disuelta en 1979 con el objetivo de crear Inversiones la Construcción (INVESCO), una sociedad por acciones de propiedad del gremio de la construcción. 
En 1958, el gremio de la construcción entregó directamente al presidente de la república Jorge Alessandri (1958-1964) un Plan Habitacional con elementos que consideraba fundamentales. Se contemplaba entre varias cosas la construcción de mayores volúmenes de vivienda por parte del Estado, la creación de una institución estatal que centralizara la actividad, dado que no existía aún el Ministerio de la Vivienda, una nueva institucionalidad financiera en materia de vivienda e incentivos tributarios para ello. En 1959 y 1960 se transformarán en el Decreto con Fuerza de Ley nro. 2 y el Sistema Nacional de Ahorro y Préstamo.

\section{Tributos: Decreto con fuerza de Ley 2 (DFL 2, 1959)}

Las formas de tributación son primordiales en el marco de la financiarización (Hudson, 2018; Reinhart y Rogoff, 2011; Zucman, 2015). En específico, el DFL 2 apuntaba a la "creación de un mercado comprador de viviendas" catalizado por el Estado que separaba entre "viviendas económicas" y viviendas de interés social. El DFL 2 señala:

"Se considerarán «viviendas económicas» (...), las que se construyen en conformidad a sus disposiciones, tengan una superficie edificada no superior a 140 metros cuadrados por unidad de vivienda y reúnan los requisitos, características y condiciones que determine el Reglamento Especial que dicte el Presidente de la República" (DFL 2, 1959, art. 1).

En definitiva, el DFL 2 plantea, entre otros incentivos, que "las rentas que produzcan las «viviendas económicas» no se considerarán para los efectos del impuesto global complementario ni adicional y estarán, además, exentas de cualquier impuesto de categoría de la Ley de Impuesto a la Renta" (DFL 2, 1959, art. 15, mayúsculas en el original). Asimismo, el DFL 2 excluye de pagar impuestos de primera categoría a las rentas de las sociedades que tengan por objetivo construir, vender o permutar viviendas económicas, por lo tanto, los socios de dichas empresas no deberán pagar dicho impuesto por participaciones o utilidades que devengan de dicha actividad (DFL 2, 1959, arts. 8 y 9). El Servicio de Impuestos Internos (SII) señala que "el impuesto de Primera Categoría grava las rentas provenientes del capital". En otras palabras, el propietario de un inmueble acogido al DFL 2 está exento de cancelar un impuesto por la posesión de dicho bien inmueble.

El DFL 2 estará vigente hasta 2010, es decir, más de cincuenta años durante los cuales, al recaer la exención tributaria sobre el bien y no sobre la persona, se permitió la acumulación de la propiedad de la vivienda. Actualmente, como se observa en la Tabla 1, los datos corroboran que el DFL 2 ha sido una herramienta que ha contribuido a la acumulación de la propiedad de la vivienda como capital. 
Tabla 1:

Contribuyentes con más de 50 propiedades acogidas al DFL 2 (2019).

\begin{tabular}{lccccccccc}
\multicolumn{10}{c}{ Propiedades por contribuyente acogido al DFL 2 } \\
\hline Rango de propiedades & $51-100$ & $101-200$ & $201-300$ & $301-400$ & $401-500$ & $501-1000$ & $\begin{array}{l}1001- \\
2000\end{array}$ & $\begin{array}{l}2001 \text { o } \\
\text { más }\end{array}$ \\
\hline Nro. de contribuyentes & 451 & 255 & 62 & 40 & 28 & 51 & 23 & 25 \\
\hline
\end{tabular}

Fuente: Oficio ordinario 02493, 3 de octubre de 2019, Subdirección de Avaluaciones.

Por otro lado, si el DFL 2 tenía por función incentivar el destino de capitales privados a la construcción de viviendas para el mercado privado, entonces las Asociaciones de Ahorro y Préstamo tenían por objetivo centralizar el capital financiero y capitalizar las exenciones contenidas en el DFL 2 a partir de la creación de nuevos actores privados en el mercado financiero y de la vivienda a petición del gremio.

\section{Sistema Nacional de Ahorro y Préstamo}

Las Asociaciones de Ahorro y Préstamo (Save and Loan) fueron parte de lo que se conoció como el Sistema Nacional de Ahorro y Préstamo. Funcionaban con fondos provenientes de un impuesto a empresas que debían destinar el 5\% de sus utilidades a construcción de viviendas obreras y que las empresas podían destinar directamente a las AAP; con ahorro capitalista, con dinero de las Cajas de Previsión y podían obtener préstamos de la Caja Central de Ahorro y Préstamo. Una muestra simplificada del flujo de capital en la Figura 3. 


\section{Figura 3.}

Flujo simplificado de capital SINAP.

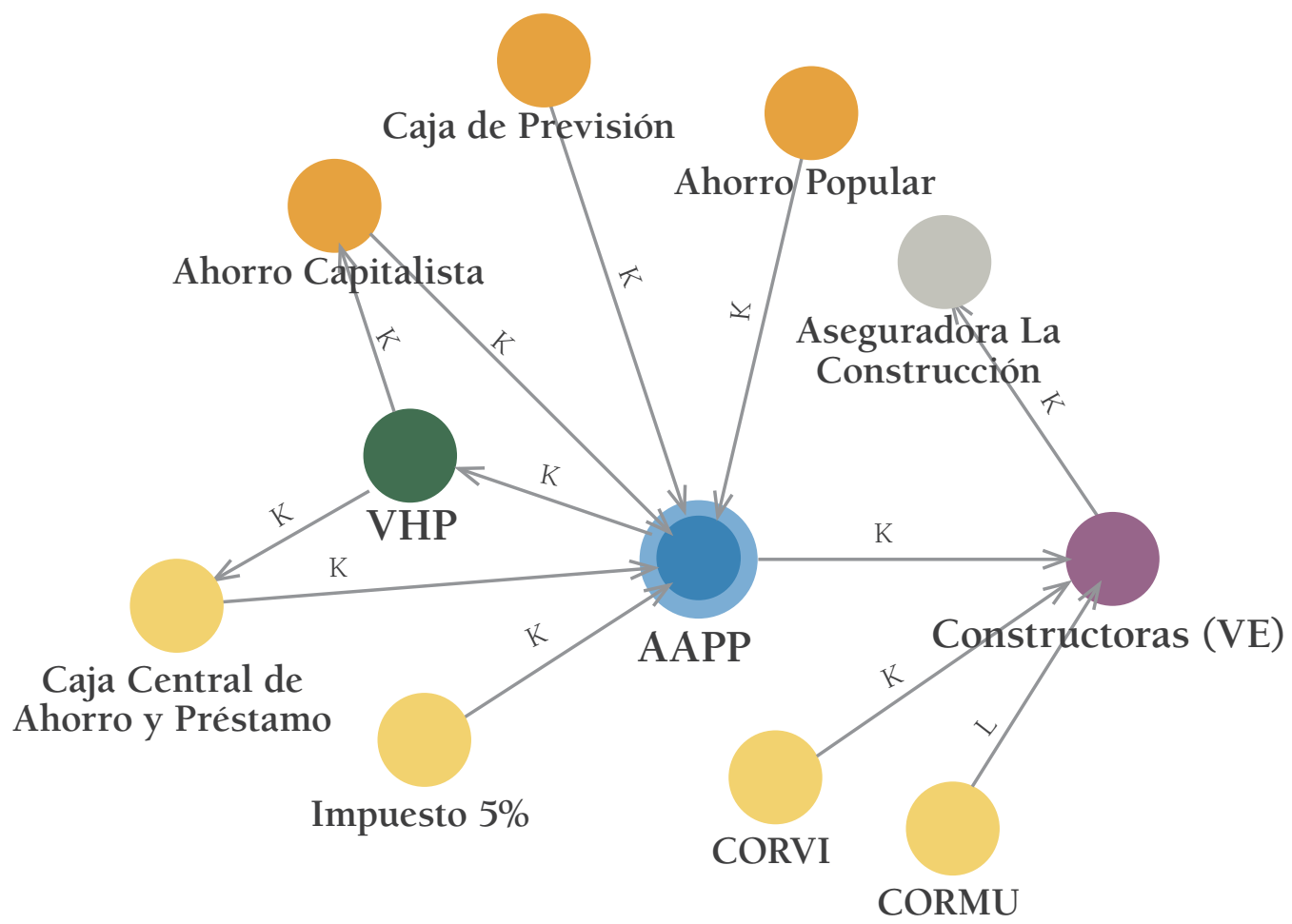

Fuente: Kornbluth, 2020a, 2021.

Si bien las AAP no estaban asociadas a la CChC se observa una relación directa entre dichas instituciones. Respecto del SINAP la CChC señala que:

"El Sistema Nacional de Ahorro y Préstamo ha ido adquiriendo, en progresión acelerada, una significación e importancia decisivas. En sus primeros tiempos -como toda iniciativa nueva- requirió de un apoyo financiero muy importante de parte de los organismos internacionales como del erario fiscal. Hoy día el SINAP se desenvuelve gracias a sus propias fuentes de recursos, derivadas del incremento que ha experimentado el ahorro directo, la normal recuperación que exhibe el servicio de los préstamos otorgados y, muy fundamentalmente, de la confianza pública que existe en la adquisición de los valores emitidos por la Caja Central y de los créditos concedidos por las Asociaciones, cuya transacción constituye lo que se denomina el Mercado Secundario de Hipotecas" (CChC, 1969, p. 15). 
El SINAP es un mecanismo bastante sofisticado para la época, tranzando inclusive instrumentos financieros derivados denominados Valores Hipotecarios Reajustables o VHR (Kornbluth, 2020a, 2021). Los valores, tanto para 1964 como para 1970 están referenciados en escudos de 1970 (Foxley, 1977, p. 11). Según datos oficiales del Banco Central (2001), el tipo de cambio de la época era de $E^{\circ}$ 12,21, lo que corresponde a USD 827.190,82 y USD 60.687.970,68 dólares de la época respectivamente. Una muestra del volumen e importancia del SINAP se observa en la Tabla 2.

Tabla 2.

\section{Indicadores SINAP.}

\begin{tabular}{lccc}
\multicolumn{4}{c}{ Indicadores de la evolución del SINAP (1962-1970) } \\
\multicolumn{1}{c}{ Item/año } & 1962 & 1964 & 1970 \\
\hline Viviendas financiadas & 1.575 & 4.644 & 12.578 \\
\hline Inversión SINAP en total invertido en vivienda & $10,4 \%$ & $23,9 \%$ & $68,5 \%$ \\
\hline Ventas netas VHR (millones de escudos de 1970) & & 10,1 & 741 \\
\hline
\end{tabular}

Fuente: Foxley (1977).

Más allá de la evidencia específica sobre instrumentos financieros derivados y el rol que llega a desempeñar el SINAP en el mercado de capitales, se observan para esta etapa numerosos cruces de directores entre este tipo de asociaciones y empresas que hacían parte de la CChC, pudiendo inclusive oponerse exitosamente al intento de legislar la inhabilidad para ejercer paralelamente cargos de esta naturaleza (Cheetham, 1971). Un ejemplo gráfico es que para el diseño e implementación del SINAP desde la CChC se convocó un grupo integrado por los directores de la CChC Guillermo Le Fort y Walter Sommerhoff (CChC, 1960, p. 8, 1961, p. 11). Posteriormente, Le Fort asumirá como vicepresidente de la Caja Central de Ahorro y Préstamo en 1960 (Cheetham, 1971, p. 147), dejando su cargo al iniciar el gobierno de Allende en $1970^{2}$.

Estas políticas, sugeridas por la CChC, se encuentran articuladas y son la base del proceso de financiarización de la vivienda en Chile. Su articulación radica en que las Asociaciones de Ahorro y Préstamo (elemento que la CChC venía discutiendo con expertos norteamericanos en el marco del Punto cuarto y la Alianza para el Progreso ${ }^{3}$ desde mediados de los años cincuenta) podían invertir en viviendas que se acogían al DFL 2 constituyendo un circuito financiero con las empresas constructoras de viviendas económicas, las cuales también contaban con exenciones tributarias. De este modo se fue asentando no sólo un modo de circulación

2 Diario Oficial, jueves 24 de diciembre de 1970, p. 7.

3 El Punto Cuarto y la Alianza para el Progreso son dos políticas de Asistencia técnica y económica del gobierno de Estados Unidos en América Latina en la década del cincuenta y sesenta. 


\section{revistainvi}

de capital financiero lo suficientemente sofisticado y con presencia de instrumentos financieros derivados que acentúa la concentración de la propiedad de la vivienda en el país (Kornbluth, 2021), sino también una expresión de la articulación institucional entre agentes privados y el Estado con el fin de crear un mercado de la vivienda (Bourdieu, 2016). Una panorámica más amplia de las políticas implementadas relacionadas con el accionar del gremio en la Tabla 3.

Tabla 3.

Implementación y discusión de leyes y políticas (1951-1973).

\begin{tabular}{|c|c|c|c|}
\hline \multicolumn{4}{|c|}{ Momentos de "promulgación» y «discusión» de políticas } \\
\hline Fase & Política & Promulgación & Discusión (CChC) \\
\hline \multirow{5}{*}{ Constitución (1951-1973) } & Asignación familiar & 1954 & 1952 \\
\hline & PRIS & 1960 & 1957 \\
\hline & DFL 2 & 1959 & 1957 \\
\hline & SINAP & 1961 & 1957 \\
\hline & Creación MINVU & 1965 & 1962 \\
\hline
\end{tabular}

Fuente: Elaboración propia en base a memorias anuales CChC (1952-1973).

\section{ReCONfiguración FinanCieRA (1973-1990)}

Durante esta etapa se evidencian la nueva Política Urbana (1979) y el nuevo Plan Laboral (1979) que generaron impactos sustantivos en materia de desarrollo urbano y trabajo en el sector de la construcción, por nombrar algunos elementos favorables de cambio para el gremio en los que tuvo oportunidad de influir (Kornbluth, 2020a).

Entre los aspectos más relevantes, la liberalización del suelo y la política de erradicaciones (Donoso y Sabatini, 1980; Morales y Rojas, 1987) son centrales para comprender lo urbano en Chile y el proceso de configuración de la ciudad neoliberal (Janoschka e Hidalgo, 2014), sin embargo, en cuanto a la financiarización más específicamente, se distinguen otros elementos que vale la pena tener en cuenta también y que parecen algo menos explorados en su diseño. Entre ellos destaca el cierre de la compañía de seguros -fundada en 1954- para crear una sociedad de inversiones (INVESCO), cuyo primer eslabón será la creación de una Administradora de Fondos de Pensiones (1980). Adicionalmente, desde el Estado se promulgará el subsidio habitacional. 


\section{*.*vis revistainvi}

\section{Diseño y promulgación del subsidio habitacional}

La política de subsidio habitacional (1978) ha sido ampliamente estudiada desde las transformaciones neoliberales (Gilbert, 2002; Janoschka e Hidalgo, 2014; Sugranyes y Rodríguez, 2005). Sin embargo, la participación del gremio de la construcción es algo más desconocida. Al respecto, un texto institucional señala:

"Con la nueva economía de mercado se habían eliminado todas las bonificaciones a los productos, lo que era crítico para la vivienda popular, pues hasta entonces se había recurrido para financiar su construcción, a una serie de subsidios ocultos o indirectos (...). Todo eso terminó con el libre mercado (...). Era preciso entonces diseñar algo nuevo. La solución surgió de Miguel Kast, Sub Director de Odeplán, quien propuso terminar con esos subsidios cruzados y convertirlos abiertamente en una ayuda del Estado no reembolsable, asignada a cada unidad construida, dentro de una normativa de puntaje que privilegiaba el ahorro y al grupo familiar. Así nació en 1977 el sistema de Subsidio Habitacional que rige hasta hoy y que significó un cambio trascendental, pues encauzó la demanda de los postulantes hacia el mercado. Se introdujo el concepto de la vivienda como un bien que se gana con el esfuerzo propio, y con un aporte estatal que se canaliza apoyando a los más necesitados en la forma de un premio por su esfuerzo. Desde su establecimiento, el 32\% de las viviendas nuevas del país han sido construidas bajo este sistema. Los programas de subsidio han entregado como promedio una base estable de entre 30 a 35 mil nuevas viviendas anuales. El subsidio habitacional significó también un nuevo impulso para un cambio que venía desde antes: la modalidad de contratación de viviendas sociales (...). A partir de 1978, los contratistas tuvieron la responsabilidad de ofrecer un proyecto completo, (concurso-oferta), en terrenos propios o de terceros, y cuya ejecución deben financiar. Este sistema financiero de ahorro popular apoyado por el Subsidio generó una competencia de ofertas que derivó en diseños más económicos y eficientes, con lo cual se lograron importantes bajas en el valor final de las viviendas sociales y en el costo de administración del sistema por parte del Estado" (CChC, 1991, pp. 90-91, mayúsculas en el original).

De la extensa cita anterior se extrae no sólo el modo en el que se implementa el subsidio habitacional y su impulso gracias a Miguel Kast (yerno de Walter Sommerhoff, fundador del gremio y diseñador del SINAP), sino también el rol económico que comienza a desempeñar a contar de su implementación financiando prácticamente un tercio de las viviendas construidas. Se observa además que años antes, la CChC ya discutía una política orientada a "fomentar la construcción de viviendas sociales" (CChC, 1975, p. 18). Al respecto una memoria institucional planteaba que:

"existe, en muchos sectores de la población, una profunda brecha, entre el valor de una vivienda y las posibilidades económicas de adquirirla. Por ello, hemos concentrado nuestros esfuerzos en señalar a las autoridades la absoluta necesidad de que se establezca un mecanismo de subsidio al comprador de vivienda de determinada condición económica" (CChC, 1976, pp. 7-8, mayúsculas en el original).

En otras palabras, al ya pensado mercado de la vivienda privada, facilitado por la exención tributaria (DFL 2) y el aval del Estado (SINAP), se suma ahora la creación de un mercado para la vivienda de interés social con capitales facilitados por este en forma de subsidios. Estos recursos financieros se sumarán a un flujo de capital financiero privado gracias a la promulgación del Decreto Ley 3.500 que crea las Administradoras de Fondos de Pensión. 


\section{*.*vis revistainvi}

\section{Creación de un flujo de capital disponible: Las AFP}

Un segundo hito está constituido por la reforma a la seguridad social de 1980, la cual contempla la creación de las Administradoras de Fondos de Pensión. El sistema de AFP constituye el principal pilar del sistema financiero chileno. Actualmente, las AFP administran el equivalente al 80\% del PIB nacional (Gálvez y Kremerman, 2020). En ese universo, la AFP controlada por el gremio de la construcción administra un 28\% de los activos totales del sistema de AFP (Superintendencia de Pensiones, 2019). Al respecto, la CChC plantea en 1976 que:

"Es un hecho unánimemente reconocido que el actual sistema de seguridad social chileno constituye un mecanismo ineficaz, discriminatorio y de elevado costo, habiendo llegado a un estado tal de crisis que hace extremadamente urgente su reemplazo. Entendiéndolo así, el Supremo Gobierno preparó un anteproyecto de «Estatuto Fundamental de Principios y Bases del Sistema de Seguridad Social» (...). Nuestra Cámara, que otorga a esta materia una prioridad esencial, se dedicó de lleno, a través de una Comisión (...). La Comisión, en la que participaron técnicos de alta categoría, llegó a la conclusión de que, si bien el Estatuto propuesto requiere, en su concepto, de algunas modificaciones, constituye en su contexto general un esquema orgánico de seguridad social y uniforma el régimen de prestaciones para todo el país con fundamento en la protección efectiva de los estados de necesidad, -motivo por el cual apoya decididamente su implementación" (CChC, 1976, p. 16).

Antes de la implementación del nuevo sistema de seguridad social, y específicamente en el rubro de la administración de las pensiones de los trabajadores, la CChC expresa que:

"El esquema de prestaciones que contempla el nuevo Sistema de Seguridad Social, las características y magnitud del flujo monetario que se originará, la inversión de enormes recursos financieros con criterio económico, la necesidad de difusión del Sistema y de promoción de la Corporación, con información permanente y sistemática a los trabajadores afiliados, han constituido las bases para el diseño de un proyecto de organización de esta nueva entidad" (CChC, 1976, pp. 32-33, mayúsculas en el original).

Por último, y con el fin de aclarar aún más la participación de la nueva entidad en el proceso de financiarización del empresariado de la construcción, cabe destacar que uno de los objetivos de la nueva entidad será "allegar preferentemente recursos al sector construcción frente a otras alternativas de inversión que pueda considerar dicha sociedad" (CChC, 1981, p. 27).

A esto se debe sumar que José Piñera, ex Ministro del Trabajo a cargo de las reformas al Código del Trabajo y a las pensiones, ejercerá entre 1982 y 1984 en el departamento de estudios del gremio como consultor (CChC, 1983, 1984). Modesto Collados, quien ya había sido Ministro de Obras Públicas (1964-1965) y Ministro de Vivienda (1965-1966) durante el gobierno de Frei (1964-1970), será elegido como Presidente del Gremio en 1982, no culminando su período para sumarse nuevamente como Ministro de Vivienda y Urbanismo (1982) y luego de Economía (1983) (Huneeus, 2005; Silva, 2010). Desde allí, Collados impulsará la política conocida como "20 con 8", por consistir en créditos a veinte años con un interés de $8 \%$ con el fin de liquidar el stock de vivienda en posesión de los bancos tras la crisis de 1982 (Kornbluth, 2020a). 
Finalmente, se debe destacar que las políticas puntualizadas (Subsidio Habitacional, reforma de la seguridad social con la consiguiente creación de una Administradora de Fondos de Pensiones) demuestran la versatilidad del gremio de la construcción y su participación en el marco del proceso de financiarización durante este período, perfeccionando los flujos de capital financiero para la vivienda. A la vez, dichas políticas demuestran la capacidad de influencia política del gremio de la construcción en la elaboración de normativas que les sean favorables en el marco de la acumulación de capital. Una panorámica más amplia de las políticas implementadas relacionadas con el accionar del gremio en la Tabla 4.

\section{Tabla 4.}

Implementación y discusión de leyes y políticas 1973-1990.

Momentos de «promulgación» y «discusión» de políticas (1973-1990)

\begin{tabular}{|c|c|c|c|}
\hline Fase & Política & Promulgación & $\begin{array}{l}\text { Discusión } \\
\text { (CChC) }\end{array}$ \\
\hline \multirow{8}{*}{$\begin{array}{l}\text { (re)configuración } \\
\text { (1973-1989) }\end{array}$} & Erradicaciones & 1977 & 1974 \\
\hline & Subsidio habitacional & 1978 & 1976 \\
\hline & Código del Trabajo & 1979 & 1975 \\
\hline & Política de Desarrollo Urbano & 1979 & 1975 \\
\hline & Ajuste a la Política de Desarrollo Urbano & 1985 & 1982 \\
\hline & Seguridad Social & 1980 & 1975 \\
\hline & Plan Trienal & 1983 & 1983 \\
\hline & «20 con $8 »$ & 1983 & 1983 \\
\hline
\end{tabular}

Fuente: Elaboración propia en base a Memorias anuales CChC (1973-1989). 


\section{*.*vis revistainvi}

\section{LA CONSOLIDACIÓN POLÍTICA DEL ORDEN FINANCIERO (1990-2012)}

Un tercer período va desde 1990 al 2012. Este período está marcado por el crecimiento de la sociedad de inversiones (INVESCO) y sus entidades de responsabilidad social empresarial, siendo una continuidad de la política de subsidio habitacional como influjos de capital financiero para el sector de la construcción. La etapa se cierra en 2012, momento de salida bursátil de la sociedad de inversiones del gremio, constituyendo la principal operación financiera de la historia del mercado chileno hasta ese momento y recaudando USD 400 millones en un día por el 33\% de la sociedad.

Durante esta etapa, el gremio inicia una expansión con inversiones en el extranjero en materia previsional (Argentina, Perú y México) y establecerá alianzas con otros grupos de negocios internacionales (City Group, Royal Sun Alliance) (CChC, 2002, p. 66), en el marco de la mundialización financiera. Sin embargo, más allá del entramado institucional de gobernanza del gremio de la construcción (el cual simplemente continúa la tendencia creciente desde la década del cincuenta), interesa destacar otras cuestiones del proceso de diseño político de los mercados en el proceso de financiarización de la vivienda y el espacio urbano. Durante esta etapa adquiere suma relevancia la promulgación de la Ley de Concesiones que se expande en distintas direcciones (sanitarias, portuarias, penitenciarias, hospitalarias, vías urbanas e interurbanas, etc.) y el leasing-leaseback como mecanismo de flujo de capital financiero para el sector de los seguros (Gasic, 2021).

\section{Concesiones: privatización y financiarización de los bienes comunes}

La ley de concesiones se hará realidad en 1991, sin embargo, esta modalidad financiarizada de construcción y explotación de infraestructura pública tiene una larga data intelectual precedente (Zrari, 2008). En efecto, durante la etapa anterior en la dictadura cívico-militar, en la memoria de 1980 la CChC planteaba la idea "de permitir la construcción de obras mediante un sistema de concesiones", y en ese sentido, señalaba que:

"Hasta el momento, se nos ha informado que se encuentra próxima a dictarse una legislación que entrega facultades especiales a S. E. el Presidente de la República a fin de fijar los criterios para llevar a cabo esta iniciativa (...). El señor Ministro del ramo nos ha solicitado que le hagamos llegar nuestras opiniones al respecto, para que, posteriormente, nos reunamos con los personeros del Ministerio que se encuentran estudiando esta materia" (CChC, 1980, p. 35, mayúsculas en el original).

La formulación de la propuesta de concesiones de infraestructura pública nació en el Departamento de Estudios de la Cámara Chilena de la Construcción. Dicha propuesta planteaba por ejemplo que: "un sistema de concesiones de Obras Públicas sólo será viable si acaso se otorgan garantías plenas a los inversionistas privados para lo cual será necesario contar con las normas legales de rango constitucional pertinentes" (CChC, 1981, p. 11). El encargado de desarrollar dicho proyecto a principios de la década del ochenta desde el Departamento de Estudios del gremio fue Carlos Hurtado Ruiz-Tagle. En 1990 el mismo Carlos Hurtado será nombrado Ministro de Obras Públicas. En este mismo año (1990), la memoria institucional declara que la CChC: "ha participado en la redacción del proyecto de reglamento de concesiones (...), y ha preparado 


\title{
*.*vis revistainvi
}

un compendio de la nueva legislación que rige al sector" (CChC, 1990, p. 19). Los datos recién presentados son corroborados por un ex presidente de la CChC entrevistado para la investigación, quien plantea sobre el sistema de concesiones que:

\begin{abstract}
"En los años noventa es la partida del sistema que es notable (...) es la visión que se tiene en la década del ochenta para desarrollar las bases de un proyecto que significara cómo Chile encara una necesidad imperiosa de infraestructura que en ese momento era dramática, en circunstancias que su presupuesto de Obras Públicas era insuficiente y tenía que priorizar otras necesidades, llegando al convencimiento -y en esto la Cámara Chilena de la Construcción tiene un rol muy activo, ya que genera los estudios- de que el sector privado, como se estaba haciendo en otras partes del mundo, iba a ser quién podía encarar la magnitud de las obras que se requerían. Se trabaja con especialistas, se preparan las bases de la ley y la primera década es clave. El gobierno toma la decisión y pone a las personas adecuadas para que comience el proceso. Posteriormente se va produciendo la complejización, ya que en principio las concesiones se planificaron para la infraestructura vial y luego se extiende a los servicios sanitarios y a otras áreas: aeroportuaria, transporte, etc. Esas áreas no estaban cubiertas en la ley inicial" (Entrevista nro. 9).
\end{abstract}

Efectivamente, al mirar la ley original se observa que la primera década es clave con una sustantiva expansión del modelo de concesiones hacia otras áreas de la infraestructura pública. Si originalmente se apuntaba a la infraestructura vial urbana e interurbana, al finalizar este período hay concesiones portuarias y aeroportuarias, sanitarias, hospitalarias, penitenciarias, edificios públicos, etc. (Kornbluth, 2020a; Zrari, 2008).

\section{Leasing, subsidios y créditos hipotecarios}

A las instituciones antes mencionadas en la estructura corporativa del gremio se suman una sociedad aseguradora, pero también dos estructuras que ya existían en su área de Responsabilidad Social Empresarial, las cuales son capaces de insertarse en el flujo de capital financiero propugnado desde el gremio de la construcción. La estructura de funcionamiento del gremio de la construcción es más compleja como se observó en la Figura 1. Al respecto, en 1994 la CChC expresaba en su memoria que:

"En materia de leasing habitacional, la Cámara estructuró medidas de coordinación con la Caja de Compensación Los Andes, la Compañía de Seguros La Construcción, la Sociedad Hipotecaria La Construcción y la Corporación Habitacional, que aseguren la máxima eficiencia operativa al momento de entrar en régimen dicho mecanismo financiero" (CChC, 1994, p. 14).

La cita explica muy bien la interacción la gobernanza corporativa del gremio y la articulación entre distintas instituciones controladas -independientemente de si forman parte de su área de Responsabilidad Social Empresarial o parte de su grupo de negocio-. Asimismo, se observa capacidad de innovación financiera que se expresa en el uso del capital proveniente del sector privado y del sector público. Un ejemplo de ello se ve en la memoria de 1995:

"El año pasado, los Ministros de Hacienda y de Vivienda y Urbanismo anunciaron el proyecto de un nuevo sistema de ahorro para la vivienda, dirigido a las familias de escasos recursos, con la creación de la Administradoras de Fondos para la Vivienda (AFV), sociedades anónimas, cuyo objetivo será administrar 


\section{*.*vis revistainvi}

los aportes de los ahorrantes interesados o no en celebrar un contrato de leasing para la vivienda, quienes podrán abrir en bancos, sociedades financieras o cajas de compensación, cuentas de ahorro para arrendamiento de vivienda con promesa de compraventa. Estas AFV se constituirán en una interesante alternativa para canalizar ahorro popular, esperándose en consecuencia un aumento de la tasa de ahorro privado, y una mayor competencia para las actuales libretas de ahorro, ya que se espera que los ahorros para vivienda depositados en estas nuevas administradoras podrán tener una rentabilidad similar a las que tienen hoy en día las cuentas de ahorro previsional de las AFP. Se busca, así, generar nuevos instrumentos financieros, acordes con las necesidades de los programas de vivienda social. Ampliando la gama y el número de instituciones oferentes de financiamiento, al incorporar a las Compañías de Leasing, Administradoras de Mutuos y Cajas de Compensación a este mercado, actualmente atendido sólo por bancos y algunas financieras. Se establece de esta manera un renovado enfoque de la subsidiariedad del Estado en materia habitacional, ampliando las responsabilidades del sector privado, tanto en materia de la producción de las viviendas sociales como en el de su funcionamiento, dejando radicada en el fisco sólo las funciones de otorgar y focalizar los subsidios y de asumir los riesgos propios del financiamiento de los sectores de menor capacidad económica" (CChC, 1995, pp. 15-16, mayúsculas en el original).

La Sociedad Hipotecaria tendrá como objetivo "el otorgamiento y administración de Mutuos Hipotecarios Endosables y otras actividades comprendidas en el financiamiento inmobiliario, especialmente el Leasing Inmobiliario de bienes inmuebles no habitacionales" (CChC, 1993, p. 49). En otras palabras, se implementarán concesiones, se creará el mecanismo de leasing, se complejizará la gobernanza corporativa del gremio y por último, el 2012, la sociedad de inversiones del gremio saldrá a bolsa convirtiéndose en la síntesis del proceso de financiarización del empresariado. A continuación, un esquema más amplio de las distintas políticas implementadas en este período y de la expansión de la política de concesiones en la Tabla 5. 


\section{Tabla 5.}

Implementación y discusión de leyes y políticas 1990-2012.

\begin{tabular}{|c|c|c|c|}
\hline \multicolumn{4}{|c|}{ Momentos de «promulgación» y «discusión» de políticas (1990-2012) } \\
\hline Fase & Política & Promulgación & Discusión (CChC) \\
\hline \multirow{14}{*}{$\begin{array}{l}\text { Consolidación } \\
\text { (1990-2012) }\end{array}$} & Concesiones & 1991 & 1980 \\
\hline & Concesiones sanitarias & 1998 & 1990 \\
\hline & Uso del subsuelo de bienes nacionales de uso público & 1997 & 1993 \\
\hline & Concesiones vías interurbanas & 1997 & 1991 \\
\hline & Concesiones portuarias y aeroportuarias & 1997 & 1993 \\
\hline & Concesiones de vías urbanas & 2000 & 1993 \\
\hline & PRMS & 1994 & 1992 \\
\hline & Aguas Lluvia & 2003 & 1999 \\
\hline & Ferrocarriles & 2006 & 1996 \\
\hline & Concesiones penitenciarias & 2003 & 2001 \\
\hline & Concesiones hospitalarias & 2006 & 2001 \\
\hline & Concesiones edificios públicos & 2004 & 2003 \\
\hline & $\begin{array}{l}\text { Plan Regulador Metropolitano de Santiago } \\
\text { (PRMS100) }\end{array}$ & 2004 & 2003 \\
\hline & Política de Desarrollo Urbano & 2014 & 2011 \\
\hline
\end{tabular}

Fuente: Elaboración propia en base a Memorias anuales CChC (1990-2011). 


\section{粼 revistainvi}

\section{Profundización financiera (2012-2018)}

Durante este período, en el marco del proceso de financiarización y desde la sociedad por acciones (ILC ex INVESCO) que controlara en un $67 \%$ luego de su salida a bolsa, el gremio de la construcción adquiere el control de dos compañías de seguros (2013) que se suman a una tercera abierta en 2011. Gasic (2021) ha demostrado la relevancia que tiene en la actualidad el leasing sobre el total de las inversiones en compañías de seguros en Chile, convirtiéndose en "la principal forma de inversión inmobiliaria de las aseguradoras en Chile" (Gasic, 2021, p. 50). Allí, se observa entre las principales a Confuturo, con el mayor portafolio inmobiliario de la industria, siendo la que, además, realizó la operación inmobiliaria más voluminosa de la historia de Chile en 2016, con la compra de diez centros comerciales por más de quinientos millones de dólares (2016).

Asimismo, en 2014 adquiere el 51\% de Banco Internacional para luego aumentar su porcentaje a un 67\% en 2018, en una tendencia hacia la diversificación institucional y la profundización financiera de sus operaciones que se pone en evidencia en su estructura corporativa con catorce entidades de Responsabilidad Social Empresarial y más de veinte sociedades controladas desde su sociedad por acciones (ILC), entre ellas, aseguradoras, fondos de pensión, banco, Isapre, prestadoras de salud, etc. (Kornbluth, 2021). Sin embargo, al analizar las memorias institucionales desde el rol político en el diseño de los marcos regulatorios de la financiarización de la vivienda y la infraestructura, destacan también otras cuestiones menos relevadas. Durante esta etapa los subsidios entregados continúan siendo numerosos y generalmente crecientes, salvo una caída en 2010 (año del terremoto 8.8 que azotó la zona centro sur del país) que repunta rápidamente desde 2012. Se pone en evidencia que el subsidio como política pública ha sido profundamente exitosa para el sector privado de la construcción como muestra la Figura 4. 


\section{粼 revistainvi}

\section{Figura 4.}

Subsidios pagados (1990-2018).

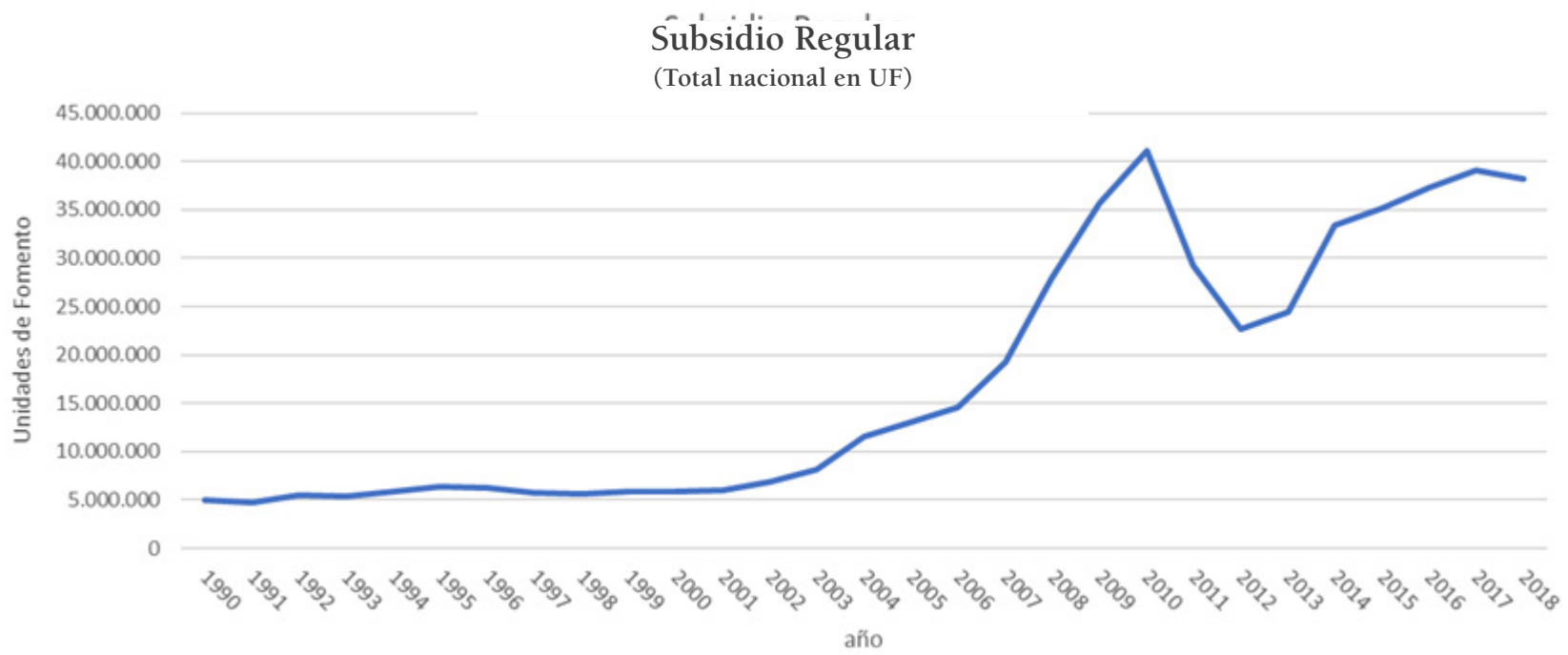

Fuente: Elaboración propia en base a Informe de Gestión DPH, publicado el 11-02-2019.

Una cuestión similar se puede apreciar en el marco de la banca privada y los créditos hipotecarios que componen alrededor de un tercio de la deuda total en el país como se observa en la Figura 5. 


\section{粼 revistainvi}

Figura 5.

Créditos hipotecarios en total de colocaciones (2010-2018).

Colocaciones por tipo de deudor, balances individuales, saldos (miles de millones de pesos)

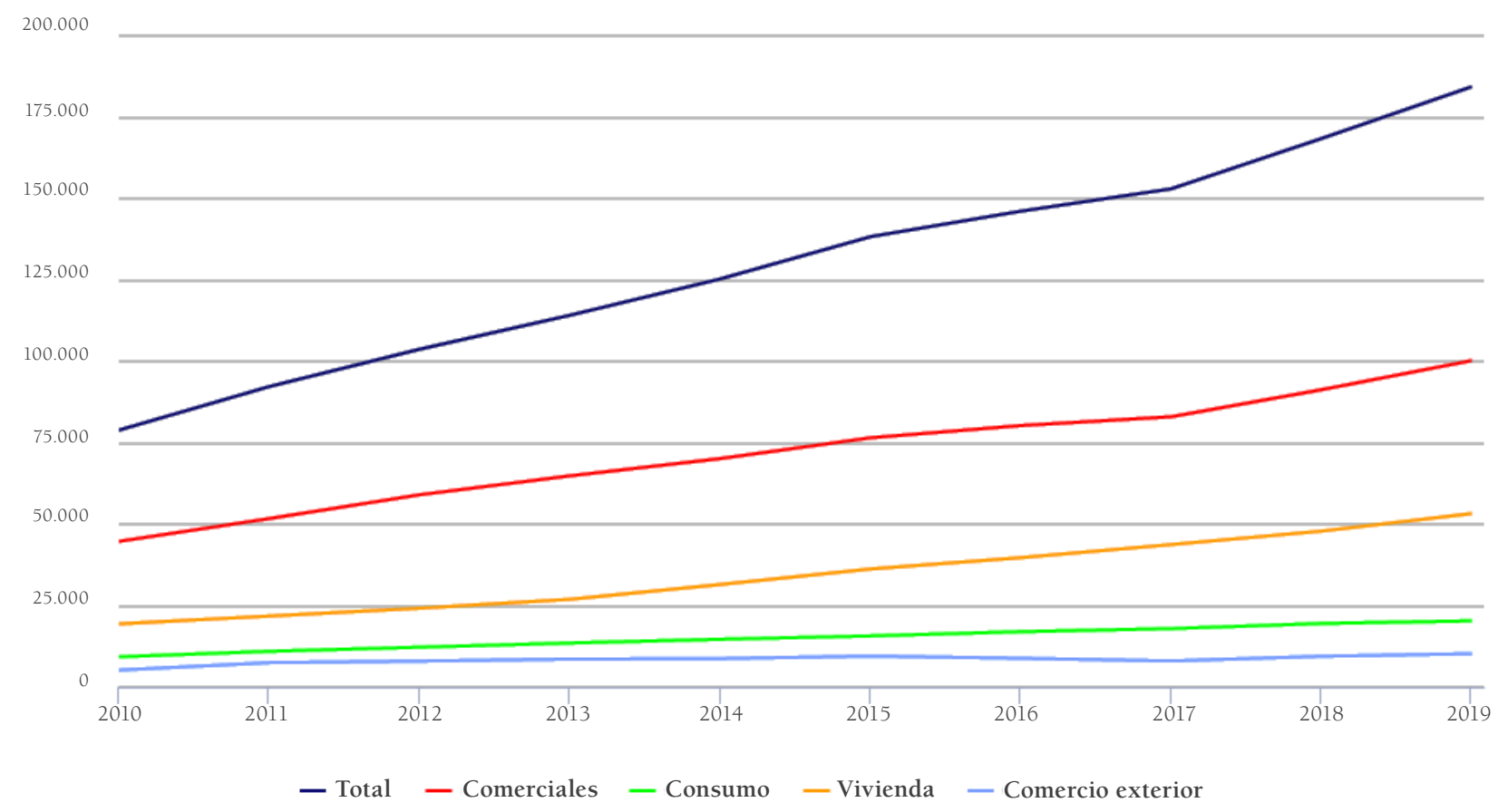

Fuente: Banco Central de Chile.

Sin embargo, en el plano del diseño político de los mercados en el proceso de financiarización, cabe destacar otro elemento fundamental: la creación del Fondo de Infraestructura. 


\section{Fondo de Infraestructura: recursos frescos y sostenibles}

El Fondo de Infraestructura, creado en 2018, es una sociedad anónima estatal con patrimonio propio controlada por el fisco (99\%) y la Corporación de Fomento (1\%), que consiste en un monto de capital exclusivamente destinado a infraestructura pública en el largo plazo. Su objetivo es:

"Desarrollar actividades empresariales de financiamiento e inversión referidas a proyectos de infraestructura, así como el desarrollo, a través de terceros no relacionados, de los servicios anexos a los mismos, incluyendo su construcción, ampliación, reparación, conservación y explotación, en conformidad y con estricta sujeción a lo dispuesto en la ley".

Un lustro antes de su creación, en 2013, la memoria del gremio de la construcción planteaba:

"Si aspiramos a que el país alcance un crecimiento sustentable, logre ser desarrollado y más competitivo, es necesario definir una política de infraestructura de largo plazo, capaz de proyectarse y mantenerse más allá de las vicisitudes políticas y de las contingencias económicas. Al mismo tiempo, es clave, tal como ocurre en los países desarrollados, que se invierta anualmente en infraestructura de uso público en torno al $6 \%$ del Producto Interno Bruto. Actualmente, en Chile sólo se invierte cerca del 3\%” (CChC, 2013, p. 24).

La Ley 21.082 que da origen al Fondo señala en su artículo $4^{\circ}$ que esta nueva entidad podrá:

"1) Financiar o invertir en proyectos de infraestructura, directamente o a través de terceros, así como elaborar y realizar los estudios necesarios para tales proyectos. 2) Construir, ampliar, reparar, conservar, explotar y desarrollar, sólo a través de terceros no relacionados, dichos proyectos de infraestructura. 3) Realizar gastos o inversiones de carácter físico o financiero, para nuevos proyectos, fomentando su construcción y desarrollo, en la forma que determine el Directorio, velando por mantener la solvencia de la empresa. 4) Emitir instrumentos financieros de deuda, de garantías y otros autorizados expresamente por el Directorio. 5) Constituir sociedades anónimas filiales o coligadas para cumplir su objeto, previa autorización de la junta de accionistas. 6) En general, ejecutar todos los actos y celebrar todos los contratos tendientes a cumplir con el objeto de la sociedad. 7) Realizar las demás actividades que expresamente se establezcan en la ley".

En la actualidad se puede señalar que para el 2019 el Fondo de Infraestructura tuvo como presupuesto asignado para su funcionamiento \$990,2 millones de pesos (aproximadamente USD 1,5 millones). Ya en 2020, su presupuesto anual, asignado por el Ministerio de Economía y el Ministerio de Hacienda, era de \$39.124,5 millones de pesos (aproximadamente USD 55 millones), los cuales son mayoritariamente destinados a "inversión financiera" compuesta por "compra de títulos y valores" (Dirección de Presupuesto). Se hace patente, entonces, que la mirada histórica del empresariado ante la actividad estatal dependerá de si compromete recursos frescos y si estos serán sostenidos y crecientes en el tiempo. Simultáneamente muestra la capacidad del empresariado de tomar decisiones sobre dichos recursos y generar acumulación privada a partir de ellos, en una tendencia iniciada en la década del cincuenta. Un esquema amplio de las principales políticas en las que ha participado el gremio activamente en la Tabla 6. 
Tabla 6.

Implementación y discusión de leyes y políticas 2012-2018.

\begin{tabular}{|c|c|c|c|}
\hline \multicolumn{4}{|c|}{ Momentos de «promulgación» y «discusión» de políticas (2012-2018) } \\
\hline Fase & Política & Promulgación & Discusión (CChC) \\
\hline \multirow{7}{*}{$\begin{array}{l}\text { Profundización } \\
\text { (2012-2018) }\end{array}$} & Plan Regulador Metropolitano de Santiago (PRMS 100) & 2013 & 2006 \\
\hline & Plan Regulador Metropolitano de Valparaiso (PREMVAL) & 2014 & 2009 \\
\hline & Aprovechamiento del Desierto & 2018 & 2002 \\
\hline & Ley de Lobby & 2014 & 2007 \\
\hline & Fondo de infraestructura & 2018 & 2001 \\
\hline & Institucionalidad regional (CORE) & 2017 & 2012 \\
\hline & Dirección de Concesiones & 2019 & 2014 \\
\hline
\end{tabular}

Fuente: Elaboración propia en base a Memorias anuales CChC (2012-2018).

\section{Conclusiones}

Desde la noción de financiarización se debe señalar que el gremio de la construcción ha tenido un desarrollo de mecanismos financieros bastante temprano, gracias a la influencia económica y política que pudo ejercer desde sus inicios en la década del cincuenta. Las asociaciones de Ahorro y Préstamo o la tributación (en este caso el DFL 2) son mecanismos que están en la prehistoria de lo que se denomina como financiarización, proceso iniciado con el desanclaje del patrón oro (1971), y que, sin embargo, entrega elementos fundamentales para entender el proceso de cambio en el régimen de acumulación capitalista contemporáneo centrado en las finanzas.

En el plano de los gremios, es relevante el poder e influencia que estos pueden tener, llegando hasta lograr diseñar los marcos normativos que regularán el proceso de financiarización. En el caso del gremio de la construcción chilena se observa una dinámica constante que se tradujo en hitos inevitables para comprender la financiarización de la vivienda y la infraestructura. A los ya citados Asociaciones de Ahorro y Préstamos y DFL 2, se suman el subsidio habitacional, Leasing, Fondos de Pensión, Aseguradoras y, en última instancia, banca; todos elementos centrales del régimen de acumulación financiero (Aalbers, 2015; Hudson, 2018; Lapavitsas, 2016). 


\section{revistainvi}

Asimismo, la creación de la Dirección de Concesiones (2019) en el Ministerio de Obras Públicas y del Fondo de Infraestructura (2018) deja un espacio relevante para analizar cómo avanza dicho modelo ya ampliamente expandido en distintas áreas en el marco del proceso de profundización financiera. Para concluir se debe señalar que la participación de esta fracción de clase ha tenido históricamente impactos relevantes no solo en el mercado de capitales, sino también en la acumulación de capital en el mercado inmobiliario y de la vivienda en general y en el espacio y la infraestructura urbana como se observa en la Figura 6.

\section{Figura 6.}

Financiarización: trayectoria empresariado de la construcción (1951-2019).

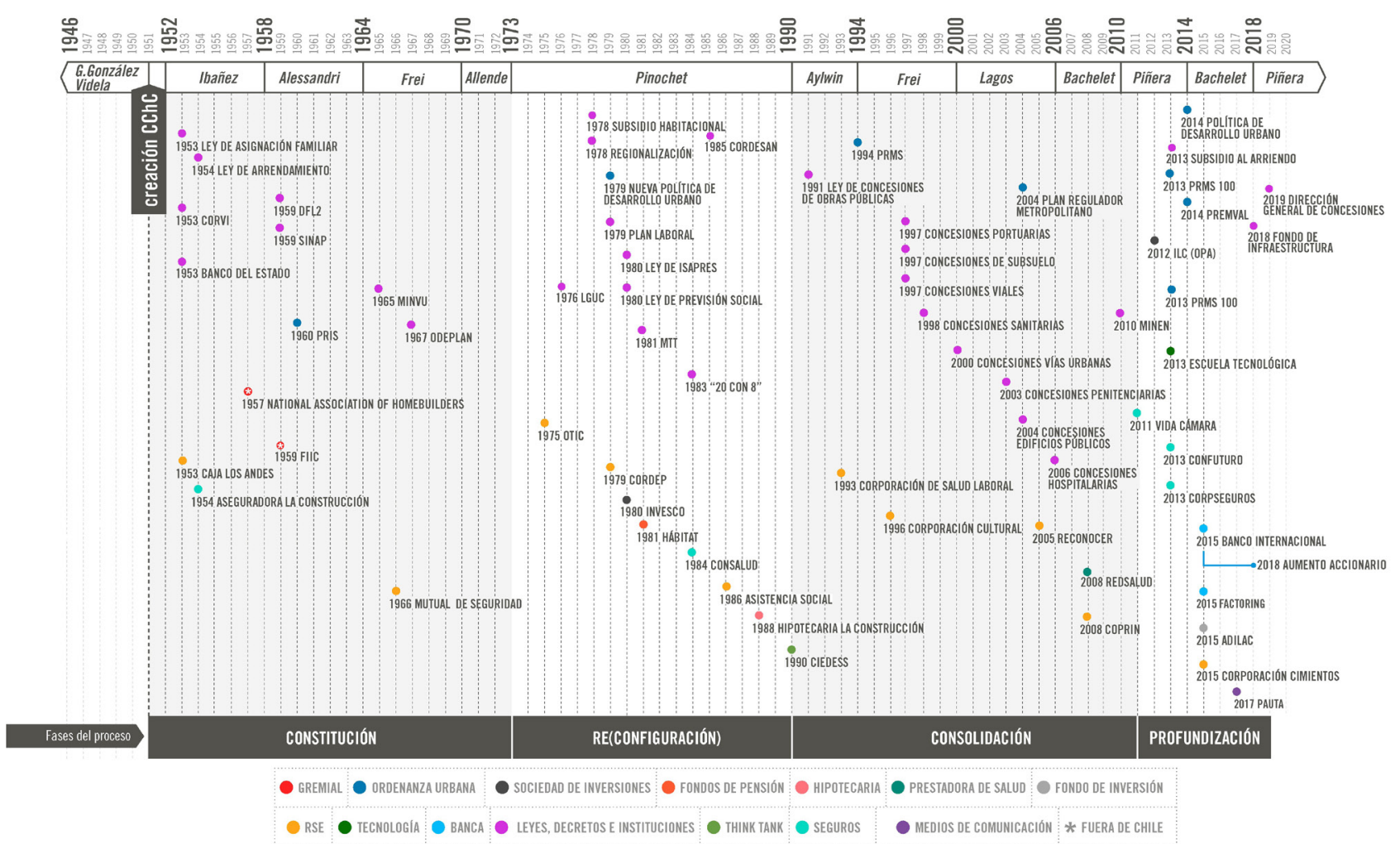

Fuente: Elaboración propia. 


\section{Referencias bibliográficas}

Aalbers, M. B. (2008). The financialization of home and the mortgage market crisis. Competition \& Change, 12(2), 148-166.https://doi.org/10.1179/102452908X289802

Aalbers, M. B. (2015). The potential for financialization. Dialogues in Human Geography, 5(2), 214-19. https:// doi.org/10.1177/2043820615588158

Alonso, L. E. y Fernández Rodríguez, C. (2018). Poder y sacrificio: los nuevos discursos de la empresa. Siglo XXI.

Appadurai, A. (2017). Hacer negocios con palabras. El fracaso del lenguaje como clave para entender el capitalismo financiero. Siglo XXI.

Arriagada, G. (1970). La oligarquía patronal chilena. Ediciones Nueva Universidad.

Arrighi, G. (1994). The long twentieth century. Money, power and the origins of our times. Verso.

Banco Central. (2001). Indicadores económicos y sociales de Chile (1960-2000). Autor.

Baran, P. y Sweezy, P. (1969). El capital monopolista: ensayo sobre el orden económico y social del Estados Unidos. Siglo XXI.

Bhattacherjee, A. (2012). Social Science research: Principles, methods and practices. University of South Florida. https://digitalcommons.usf.edu/oa textbooks/3/

Bourdieu, P. (2016). Las estructuras sociales de la economía. Ediciones Manantial

Brenner, N., Peck, J. y Theodore, N. (2010). After neoliberalization? Methodological strategies for the investigation of contemporary regulatory transformations. Globalizations, 7(3), 327-345. https://doi. org/10.1080/14747731003669669

Brenner, N.yTheodore, N. (2002). Cities and the geographies of "actually existing neoliberalism. Antipode, 34(3), 349-379. https://doi.org/10.1111/1467-8330.00246
Caffentzis, G. (2018). Los límites del capital: deuda, moneda y lucha de clases. Tinta Limón.

Cámara Chilena de la Construcción. (1952-2018). Memoria anual. Centro de documentación Cámara Chilena de la Construcción.

Cheetham, R. (1971). El sector privado de la construcción: patrón de dominación. EURE, 1(3). http://www.eure.cl/index.php/eure/article/view/832

Chesnais, F. (2001). La mundialización financiera. Genesis, costo y desafíos. Losada.

Chesnais, F. (2017). Finance capital today. Corporations and banks in the global slump. Haymarket Books.

Cortes Terzi, A. (2000). El circuito extrainstitucional del poder. CESOC.

Donoso, F. y Sabatini, F. (1980). Santiago: empresa inmobiliaria compra terrenos. EURE, 7(20). https://www. eure.cl/index.php/eure/article/view/900

Fernández, R. y Aalbers, M. (2016). Financialization and housing: Between globalization and varieties of capitalism. Competition \& Change, 20(2) 71-88. https:// doi.org/10.1177/1024529415623916

Flick, U. (2014). Qualitative data analysis. Sage.

Foster, J. B. (2007). The financialization of capitalism. Monthly Review, 58(11). https://monthlyreview.org/2007/04/01/ the-financialization-of-capitalism/

Foster, J. B. (2008). The financialization of capital and the crisis. Monthly Review, 59(11).

https://monthlyreview.org/2008/04/01/ the-financialization-of-capital-and-the-crisis/

Foster, J. B. (2010). The financialization of accumulation. Monthly Review, 62(5). https://monthlyreview. org/2010/10/01/the-financialization-of-accumulation/ 
Foxley, J. (1977). SINAP: características financieras e impacto monetario. Departamento de Economía, Universidad de Chile.

Gálvez, R., \& Kremerman, M. (2020). ¿AFP para quién? Dónde se invierten los fondos de pensiones en Chile. Documentos de Trabajo del Área de Seguridad Social. Fundación Sol. https://fundacionsol.cl/blog/ estudios-2/post/afp-para-quien-2020-6130

Gasic, I. (2021). Producción inmobiliaria, intermediación financiera y reservas de suelo en Santiago de Chile. Scripta Nova, 25(1), 33-57. https://doi.org/10.1344/ $\underline{\mathrm{sn} 2021.25 .32242}$

Garretón, M. (2017). City profile: Actually existing neoliberalism in Greater Santiago. Cities, 65, 32-50. https://doi.org/10.1016/j.cities.2017.02.005

Gilbert, A. (2002). Power, ideology and the Washington consensus: The development and spread of Chilean housing policy. Housing Studies, 17(2), 305-324. https://doi.org/10.1080/02673030220123243

Hall, P. y Soskice, D. (2001). Varieties of capitalism. The institutional foundations of comparative advantage. Oxford University Press.

Hilferding, R. (1963). El capital financiero. Tecnos.

Hudson, M. (2018). Matar al huésped. Cómo la deuda y los parásitos financieros destruyen la economía local. Capitán Swing.

Huneeus, C. (2005). El régimen de Pinochet. Sudamericana.

Instituto Nacional de Estadísticas (2019). Ocupados según rama de actividad económica. https://stat.ine.cl/Index. aspx?lang $=e s \& S u b S e s s i o n I d=78 \mathrm{e} 0518 \mathrm{e}-\mathrm{d} 028-4 \mathrm{bf} 8-$ 8d80-444b7277907c

Janoschka, M. e Hidalgo, R. (2014). La ciudad neoliberal. Estímulos de reflexión crítica. En M. Janoschka, y R. Hidalgo, La ciudad neoliberal. Gentrificación y exclusión en Santiago de Chile, Buenos Aires, Ciudad de México y Madrid. Pontificia Universidad Católica de Chile-Universidad Autónoma de Madrid.
Kornbluth, D. (2020a). Neoliberalización y acumulación capitalista: el caso de la Cámara Chilena de la Construcción (1951-2018). (Tesis doctor en Ciencias Sociales, Universidad de Chile, Santiago). https://repositorio. uchile.cl/handle/2250/178860

Kornbluth, D. (2020b). Capital financiero y clase dominante en Rudolph Hilferding: aportes para una aproximación política a los procesos de financiarización del capitalismo mundial. Actuel Marx Intervenciones, (28), 103-125.

Kornbluth, D. (2021). Gobernanza corporativa, capital financiero y empresariado de la construcción en Chile. Scripta Nova, 25(1). https://doi.org/10.1344/ $\underline{\operatorname{sn} 2021.25 .32231}$

Lapavitsas, C. (2016). Beneficios sin producción: cómo nos explotan las finanzas. Traficantes de Sueños.

Lazzarato, M. (2015). Gobernar a través de la deuda. Tecnologías de poder del capitalismo neoliberal. Amorrortú.

Lefebvre, H. (2013). La producción del espacio. Capitán Swing.

López-Morales, E. y Gasic, I. (2021). Introducción: el complejo urbano financiero inmobiliario en América Latina. Scripta Nova, 25(1). https://doi.org/10.1344/ $\underline{\operatorname{sn} 2021.25 .34240}$

López Morales, E. (2015). Suelo urbano y segregación residencial: hacia una agenda de integración social para zonas centrales metropolitanas chilenas. Ciudades, 18(1), 197-213. https://doi.org/10.24197/ ciudades.18.2015.197-213

Lucarelli, S. (2009). La financiarización como forma de biopoder. En A. Fumagalli, S. Lucarelli, C. Marazzi, S. Mezzadra, A. Negri y C. Vercellone, La gran crisis de la economía global. Mercados financieros, luchas sociales y nuevos escenarios políticos (pp. 125-148). Traficantes de Sueños.

Lukas, M. (2017). Las nuevas periferias urbanas: territorios en disputa. En W. Imilan, J. Larenas, G. Carrasco, y S. Rivera (Eds.), ¿Hacia dónde va la vivienda? Nuevos desafíos 
en el hábitat residencial. Instituto de la Vivienda, Facultad de Vivienda y Urbanismo, Universidad de Chile.

Magdoff, H. y Sweezy, P. (1987). Stagnation and the financial explosion. Monthly Review Press.

Marx, K. (1973). El capital. Crítica de la economía política. Tomo I. Fondo de Cultura Económica

Marx, K. (2015). Manuscritos económico-filosóficos de 1844. Ediciones Colihue.

McLean, B. (2013). Tu casa como un cajero automático: el mito de la propiedad de la vivienda. En J. Byrne, (Dir). Occupy Wall Street. RBA.

Méndez, R. (2018). La telaraña financiera. Una geografía de la financiarización y su crisis. RIL editores.

Morales, E., y Rojas, S. (1987). Relocalización socioespacial de la pobreza. Política estatal y presión popular (1979-1985). En J. Chateau, B. Gallardo, E. Morales, C. Piña, H. Pozo, S. Rojas, D. Sánchez y T. Valdés. Espacio y poder. Los pobladores. FLACSO.

Navarrete-Hernández, P. y Toro, F. (2019). Urban systems of accumulation: Half a century of Chilean neoliberal urban policies. Antipode, 51(3), 899-926. https://doi.org/10.1111/anti.12504

Polanyi, K. (2017). La gran transformación. Los orígenes políticos y económicos de nuestro tiempo. Fondo de Cultura Económica.

Reinhart, C. y Rogoff, K. (2011). Esta vez es distinto: ocho siglos de necedad financiera. Fondo de Cultura Económica.

Roubini, N. y Mihm, S. (2010). Cómo salimos de ésta. Planeta.

Schneider, B. R. (2009). Hierarchical market economies and varieties of capitalism in Latin América. Journal of Latin American Studies, 3(41), 553-575. https://doi. org/10.1017/S0022216X09990186

Schreier, M. (2014). Qualitative content analysis. En U. Flick, Qualitative data analysis. Sage.
Silva, P. (2010). En el nombre de la razón. Tecnócratas y politica en Chile. Ediciones Universidad Diego Portales

Sugranyes, A. y Rodríguez, A. (2005). Los con techo. Un desafio para la politica de vivienda social. Ediciones Sur.

Superintendencia de Pensiones. (2019). Estadísticas sistema de pensiones, estadísticas financieras de las AFP. Autor. https://www.spensiones.cl/apps/loadEstadisticas/loadFecuAFP.php?menu=sci\&menuNl=estfinafp\&menuN2 = NOID\&orden $=30$ \&perio-

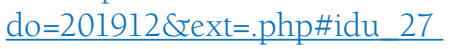

Sweezy, P. (1973). Teoría del desarrollo capitalista. Fondo de Cultura Económica.

Theodore, N., Peck, J., y Brenner, N. (2009). Urbanismo neoliberal: La ciudad y el imperio de los mercados. Temas Sociales, (66), 1-11. http://www.sitiosur.cl/ vistasur.php?opc=/publicaciones/Temas Sociales/ TemasSociales066\&id $=3532$

Torrance, M. I. (2008). Forging glocal governance? Urban infrastructures as networked financial products. International Journal of Urban and Regional Research, 32(1), 1-21. https://doi. org/10.1111/j.1468-2427.2007.00756.x

Wright, E. O. (2018). Comprender las clases sociales. Akal.

Zeitlin, M. (1980). On classes, class conflict, and the State: An introductory note. En Classes, class conflict an the State. Empirical studies in class analysis. Winthrop Publishers.

Zrari, S. (2008). La política chilena de concesiones viales: ¿mimetismo o singularidad institucional? Nuevo Mundo, Mundos Nuevos. https://doi.org/10.4000/ nuevomundo.11572

Zucman, G. (2015). La riqueza escondida de las naciones: cómo funcionan los paraísos fiscales y qué hacer con ellos. Siglo XXI. 


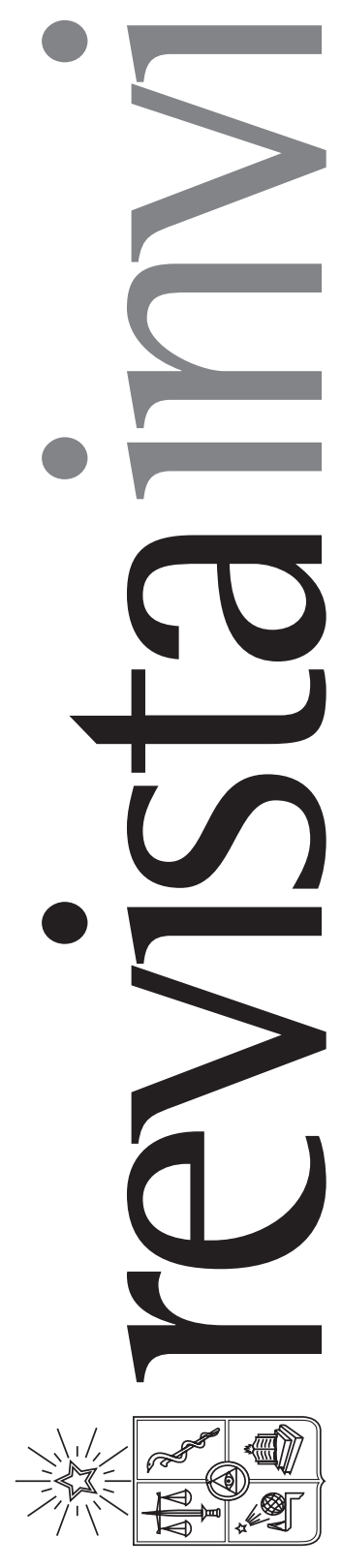

Revista INVI es una publicación periódica, editada por el Instituto de la Vivienda de la Facultad de Arquitectura y Urbanismo de la Universidad de Chile, creada en 1986 con el nombre de Boletín INVI. Es una revista académica con cobertura internacional que difunde los avances en el conocimiento sobre la vivienda, el hábitat residencial, los modos de vida y los estudios territoriales. Revista INVI publica contribuciones originales en español, inglés y portugués, privilegiando aquellas que proponen enfoques inter y multidisciplinares y que son resultado de investigaciones con financiamiento y patrocinio institucional. Se busca, con ello, contribuir al desarrollo del conocimiento científico sobre la vivienda, el hábitat y el territorio y aportar al debate público con publicaciones del más alto nivel académico.

Directora: Dra. Mariela Gaete Reyes, Universidad de Chile, Chile Editor: Dr. Luis Campos Medina, Universidad de Chile, Chile

Editores asociados: Dr. Gabriel Felmer, Universidad de Chile, Chile.

\section{Dr. Pablo Navarrete, Universidad de Chile, Chile.}

Dr. Juan Pablo Urrutia, Universidad de Chile, Chile

Coordinadora editorial: Sandra Rivera, Universidad de Chile, Chile.

Asistente editorial: Katia Venegas, Universidad de Chile, Chile.

\section{COMITÉ EDITORIAL:}

Dr. Victor Delgadillo, Universidad Autónoma de la Ciudad de México, México.

Dra. María Mercedes Di Virgilio, CONICET/ IIGG, Universidad de Buenos Aires, Argentina. Dra. Irene Molina, Uppsala Universitet, Suecia.

Dr. Gonzalo Lautaro Ojeda Ledesma, Universidad de Valparaíso, Chile.

Dra. Suzana Pasternak, Universidade de São Paulo, Brasil.

Dr. Javier Ruiz Sánchez, Universidad Politécnica de Madrid, España.

Dra. Elke Schlack Fuhrmann, Pontificia Universidad Católica de Chile, Chile.

Dr. Carlos Alberto Torres Tovar, Universidad Nacional de Colombia, Colombia.

Sitio web: http://www.revistainvi.uchile.cl/

Correo electrónico: revistainvi@uchilefau.cl

Licencia de este artículo: Creative Commons Atribución-Compartirlgual 4.0

Internacional (CC BY-SA 4.0) 